\title{
Distribution and reproduction of four intertidal crabs (Crustacea, Brachyura) in the Tonda River Estuary, Japan
}

\author{
Y. Fukui \& K. Wada \\ Seto Marine Biological Laboratory, Kyoto University, Shirahama, Wakayama 649-22, Japan
}

\begin{abstract}
Possible relations between habitat and life history attributes of 4 estuarine crabs, Deiratonotus tondensis Sakai, Hemigrapsus penicillatus (De Haan), Ptychognathus ishii Sakai and Ptychognathus capillidigitatus Takeda were investigated. Although all species inhabited intertidal cobble shores in the Tonda River Estuary, central Japan, D. tondensis dominated the upper reaches, whereas the others were prevalent in the lower reaches. All species grew rapidly after settlement, bred after their first overwintering, and had annual breeding cycles. Egg size decreased in the order $D$. tondensis, $P$. ishii, $H$. penicillatus, $P$. capillidigitatus. The number of eggs per brood in same-sized females decreased in the order $P$. capillidigitatus, $P$. ishii or $H$. penicillatus, $D$. tondensis. Reproductive effort per year was estimated to be highest in $D$. tondensis among the 4 species. The relatively unstable environment of the upper reaches, as shown by greater cobble movement, may have favored higher reproductive effort.
\end{abstract}

\section{INTRODUCTION}

Environmental conditions such as salinity, temperature and current velocity change along the length of an estuary, and are often considered to be the factors which limit the distribution and abundance of estuarine organisms (e.g. Lauff 1967, Day 1981). Estuarine species are also under tidal influence and may show species-specific vertical distributions (Little \& Smith 1980). Brachyuran crabs dominate the benthic fauna of temperate and tropical estuaries and, while their horizontal and/or vertical distributions have been investigated by many authors for soft sediment shores (e.g. Snelling 1959, Ono 1962, 1965, Griffin 1971), there have been relatively few studies of the distribution of crabs on cobble or boulder shores (Jones 1977).

Estuarine crabs have previously been studied with a view to revealing the effect of habitat on the evolution of life history attributes of crustaceans. Intra- and interspecific comparisons of life history patterns have been made between high and low tide levels (Pillay \& Ono 1978, Seiple 1979), between estuarine and marine shores (Jones 1980, Simons \& Jones 1981), and between high and low latitudes (Jones \& Simons 1983). However, variation of life history patterns for species along the length of an estuary has not been studied. This paper describes the distribution, growth and reproduction of 4 species of crabs which inhabit an estuarine intertidal cobble shore, and discusses their life history attributes in relation to differences in habitat.

\section{STUDY AREA AND METHODS}

The study area was the Tonda River Estuary $\left(33^{\circ} 38^{\prime} \mathrm{N}, 135^{\circ} 24^{\prime} \mathrm{E}\right)$, central Japan (Fig. 1). Annual river flow for 1984 was estimated as $1.47 \times 10^{8} \mathrm{~m}^{3}$ (Wakayama Prefectural Public-work Office at Tanabe, unpubl. data). Tidal range at the estuary mouth is $+211 \mathrm{~cm}$ to $-17 \mathrm{~cm}$ above chart datum (Japan Meteorological Agency 1983). Ten stations were established at regular intervals from $0.8 \mathrm{~km}$ outside the estuary mouth to $3.1 \mathrm{~km}$ up the river. The intertidal area throughout was covered mostly with cobbles. There was little variation in cobble size between stations, and most were less than $25 \mathrm{~cm}$ in diameter (boulders larger than $25 \mathrm{~cm}$ were scattered at Sts 1 and 2).

Temperature and salinity of the surface water at high and low tides were measured for 6 or 7 stations bimonthly from January 1981 to January 1982. In July 


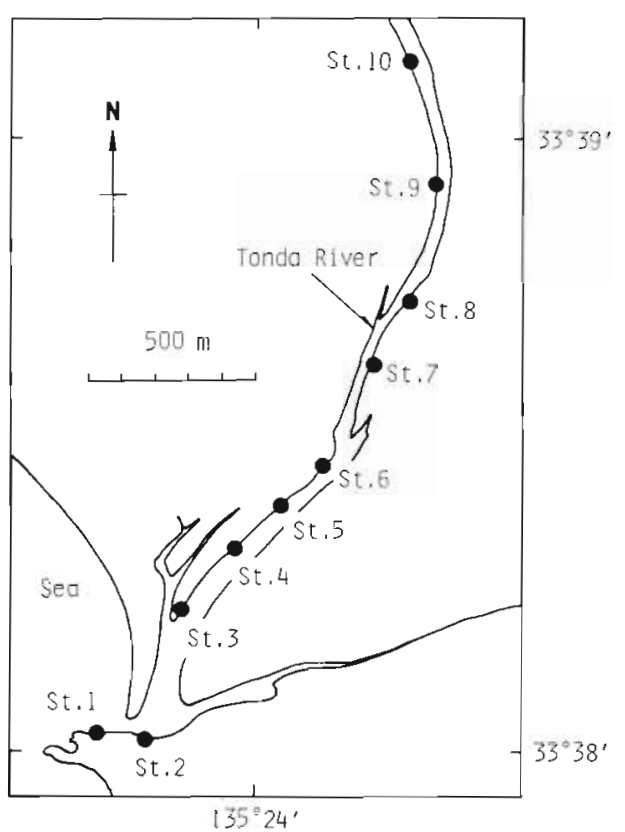

Fig. 1. Map of Tonda River Estuary, showing location of sampling stations

1981, these data were obtained from all 10 stations, and data for the bottom water at mid-tide level were also measured at high tide. Current velocity was measured at Sts 2 to 5 during flood and ebb tides on September 25, 1984 (low discharge period) and at low tide on July 4, 1985 (high discharge period). To determine cobble movements, 4 permanent quadrats, each measuring $50 \times 50 \mathrm{~cm}$, were established at mid-tide level at each of Sts 3 to 5, and photographs of the cobbles in the quadrats were taken at intervals of 15 to $41 \mathrm{~d}$ from September 1984 to September 1985. The cobbles were classified by mean diameter as 'large' (11 to $15 \mathrm{~cm}$ ) and 'small' (6 to $10 \mathrm{~cm}$ ), and the percentage of cobbles that had moved during each interval was calculated for each group.

A survey of the general crab distribution along the length of the estuary was carried out at Sts 1 to 9 during daytime spring low tides in July 1981. At each station, four 5 min searches were made at mid-and low-tide levels, and all crabs collected were recorded on the species and the number of individuals. The river bed between Sts 3 and 4 was also sampled by diving for about 1 h.

Four crab species were common, Deiratonotus tondensis Sakai, Hemigrapsus penicillatus (De Haan), Ptychognathus ishii Sakai and Ptychognathus capilLidigitatus Takeda, and these were investigated further to follow temporal changes in densities and size-frequency distributions. Crabs were sampled monthly from June 1980 to June 1981 at Sts 3 to 5; in May and June 1981 at St. 6; and bimonthly from August 1981 to September 1982 at St. 2. At each station, 2 to 4 equally- spaced sampling points were established along an intertidal cross-shore line, and 2 quadrats of $50 \times 50 \mathrm{~cm}$ were set at each point. In each quadrat, cobbles within a depth of about $20 \mathrm{~cm}$ were turned over to capture crabs. Crabs were fixed immediately in $10 \%$ formalin and later preserved in $70 \%$ ethanol. Each specimen collected was identified (Sakai 1976, 1983, Takeda 1984), measured (maximum carapace width [CW]) to the nearest $0.1 \mathrm{~mm}$ with hand calipers or a micrometer under a binocular microscope, and sexed. Specimens smaller than CW $4 \mathrm{~mm}$ were difficult to sex and were arbitrarily classed as juveniles.

Survival rate after settlement for each species was estimated from the results of the temporal density change obtained from the regular sampling points of Sts 2 to 5 . The monthly change in crab density at each station was followed separately for 2 periods of the year: before and after the autumn when recruitment almost ceased. In the former period, new recruits were excluded from the density, using the method of sizefrequency analysis described by Cassie (1954). On the assumption that survival rate is constant for each species, the regression line between time (d) and the natural logarithm of density was estimated for each of the 2 periods; the pooled slope was calculated using analysis of covariance, and used as an index of survival rate. (The slope equals the natural logarithm of daily survival rate.)

The wet weights of ovigerous females with and without eggs were measured, and the weight of a brood was calculated from these 2 values. The developmental stages of eggs were categorized following the procedure adopted by Jones (1980) as: (1) Stage I: newly deposited, filled with yolk; (2) Stage II: a yolk-free part present; (3) Stage III: eye pigment visible. The number of eggs per brood was determined by direct counting and wet weight estimation. In the wet weight estimation, a sample of about 1000 eggs were weighed and counted, and then the number of eggs were calculated from the total brood weight and the reference sample weight. Egg size was measured in the living crab. For each species, 4 to 18 ovigerous females with Stage I or Stage IIl eggs were collected, 10 eggs were taken at random from each brood, and the lengths and widths were measured to the nearest $0.001 \mathrm{~mm}$ with a profile projector.

From June to August 1981, 10 males and 10 females of each species, marked individually by sticking tape of various shapes on the carapace, were kept in a tank measuring $50 \times 30 \times 20 \mathrm{~cm}$. Sea water was used as the medium for Hemigrapsus penicillatus; about $50 \%$ sea water for the others. Water temperature was not controlled, but was measured each day. Female crabs were examined at about $3 \mathrm{~d}$ intervals to note times of egg oviposition and hatching, from which the incuba- 
tion period was calculated. The number of broods per year $(B)$ was estimated by the following equation:

$$
\mathrm{B}=\sum_{i=\mathrm{a}}^{\mathrm{b}} \frac{\mathrm{Mi}}{\mathrm{L} i} \mathrm{Ri}
$$

where $\mathrm{Mi}=$ the length of the $i$ th month; $\mathrm{I} i=$ the incubation period in the $i$ th month; $\mathrm{R} j=$ the ratio of ovigerous females to total adult females in the ith month; $a$ and $b=$ the first and the last month, respectively, of the breeding season. Adult females correspond to females which have overwintered at least once, since females of all the species matured after their first overwintering, as shown in the following results.

\section{RESULTS}

\section{Physico-chemical parameters}

Surface water temperature tended to be lower upriver than at the estuary mouth at both high and low tides (Fig. 2); the difference between the innermost and the outermost stations was 0.2 to $4.4 \mathrm{C}^{\circ}$. Temperature varied greatly, however, with season and ranged
Table 1. Water current velocity $\left(\mathrm{cm} \mathrm{s}^{-1}\right)$ at Sts 2 to 5 on Sep 25, 1984 and Jul 4, 1985

\begin{tabular}{|lcccc|}
\hline & St. 2 & St. 3 & St. 4 & St. 5 \\
\hline Sep 25, 1984 & & & & \\
$\quad$ Ebb tide & 2 & $7-8$ & $10-18$ & $15-22$ \\
$\quad$ Flood tide & $2-4$ & $7-9$ & $3-4$ & 4 \\
$\begin{array}{c}\text { Jul 4, 1985 } \\
\text { Low tide }\end{array}$ & $33-64$ & - & $54-80$ & $42-100+$ \\
\hline
\end{tabular}

from 8.0 to $25.2^{\circ} \mathrm{C}$. In July 1981 , bottom water temperature was 0.6 to $1.7 \mathrm{C}^{\circ}$ higher than surface water at 3 down-river stations.

The salinity gradient of surface water along the river was acute in January, falling from above $20 \%$ at the mouth at high tide to $0.9 \%$ within $1.6 \mathrm{~km}$ up-river (Fig. 2). From March to November, salinity was below $10 \%$ throughout the estuary. Bottom water salinity measured in July 1981 was 5.6 to $19.3 \%$ higher than surface salinity at 3 down-river stations.

Current velocity was higher at the up-river stations (Table 1). In the low discharge period (September 1984), current velocity was below $10 \mathrm{~cm} \mathrm{~s}^{-1}$ throughout the estuary during flood tide. In the high discharge

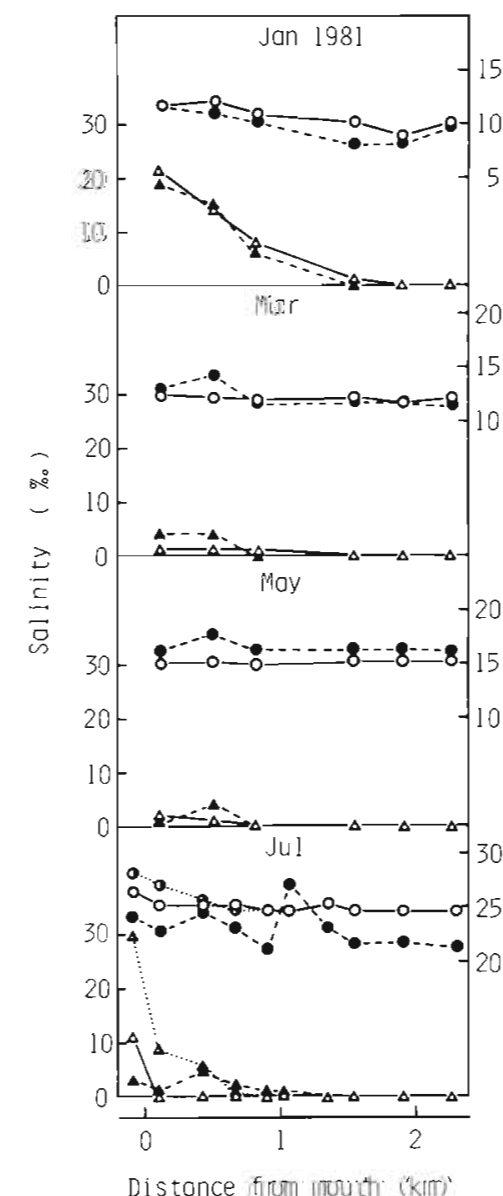

Distonce from mouth $(\mathrm{km})$

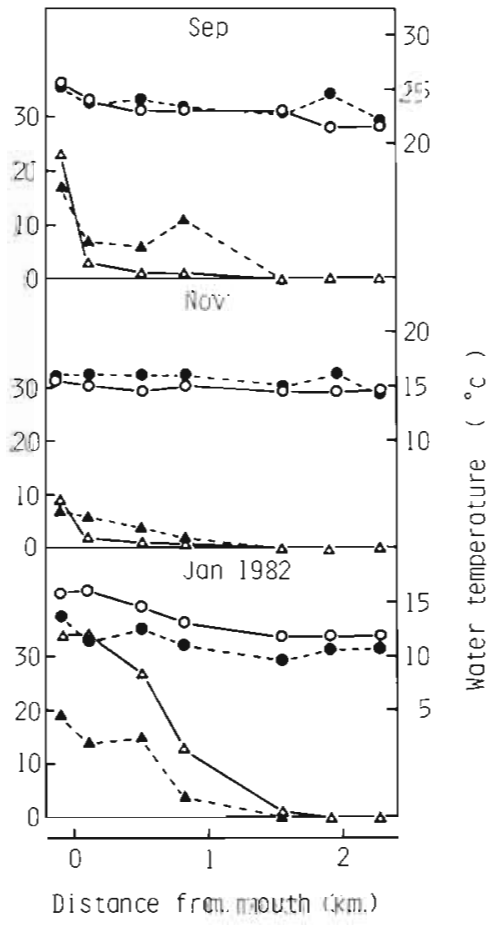

Fig. 2. Variations in water temperature (circles) and salinity (triangles) along the river from Jan 1981 to Jan 1982. Open and solid marks represent the values of the surface water at high and low tides, respectively, and half-solid marks those of the bottom water at high tide 
period (July 1985), current velocity at all stations was greater than in the low discharge period.

\section{Cobble movements}

High values $(>50 \%)$ of cobble movement in the quadrats were recorded more frequently at the up-river stations than at the down-river stations; all surface cobbles at Sts 4 and 5 moved between June 18 and July 17 (Table 2). Small cobbles of 6 to $10 \mathrm{~cm}$ mean diameter moved more frequently than large ones of 11 to $15 \mathrm{~cm}$ diameter, and their movements occurred in almost all seasons at all stations. The period when large cobble movements occurred was considerably restricted, though it was longer at the up-river stations.

\section{General crab distribution}

The 4 species - Deiratonotus tondensis, Hemigrapsus penicillatus, Ptychognathus ishii and Ptychognathus capillidigitatus - occurred within the range of
St. 1 to St. 7 but were absent from Sts 8 and 9 (Table 3). However, there were some differences in distribution among species. $D$. tondensis increased up-river with a peak in abundance at Sts 5 and 6 . $H$. penicillatus was common throughout from St. 2 to St. 6 and also occurred at St. 1. P. ishii was most abundant at the middle level of St. 2, though it was recorded at all stations between Sts 2 and 6. P. capillidigitatus decreased in abundance with increasing distance from the mouth and was absent from Sts 6 and 7 . In the subtidal cobble area between Sts 3 and 4 , only 1 individual $D$. tondensis, $3 \mathrm{H}$. penicillatus, and $1 P$. capillidigitatus were found.

\section{Seasonal distribution change}

Deiratonotus tondensis (Fig. 3)

Juvenile crabs $(<4 \mathrm{~mm}$ in carapace width [CW]) were collected in abundance at the up-river stations, with maximum juvenile densities of 61 crabs per $0.5 \mathrm{~m}^{2}$ and 25 crabs $0.5 \mathrm{~m}^{-2}$ recorded at Sts 4 and 5 respec-

Table 2. Percentage of moved cobbles recorded nearly monthly from Sep 1984 to Sep 1985 at Sts 3 to 5 . Cobbles are classed as large (11 to $15 \mathrm{~cm}$ mean diameter) or small ( 6 to $10 \mathrm{~cm}$ mean diameter). Numbers in parentheses indicate sample size at the beginning of the interval

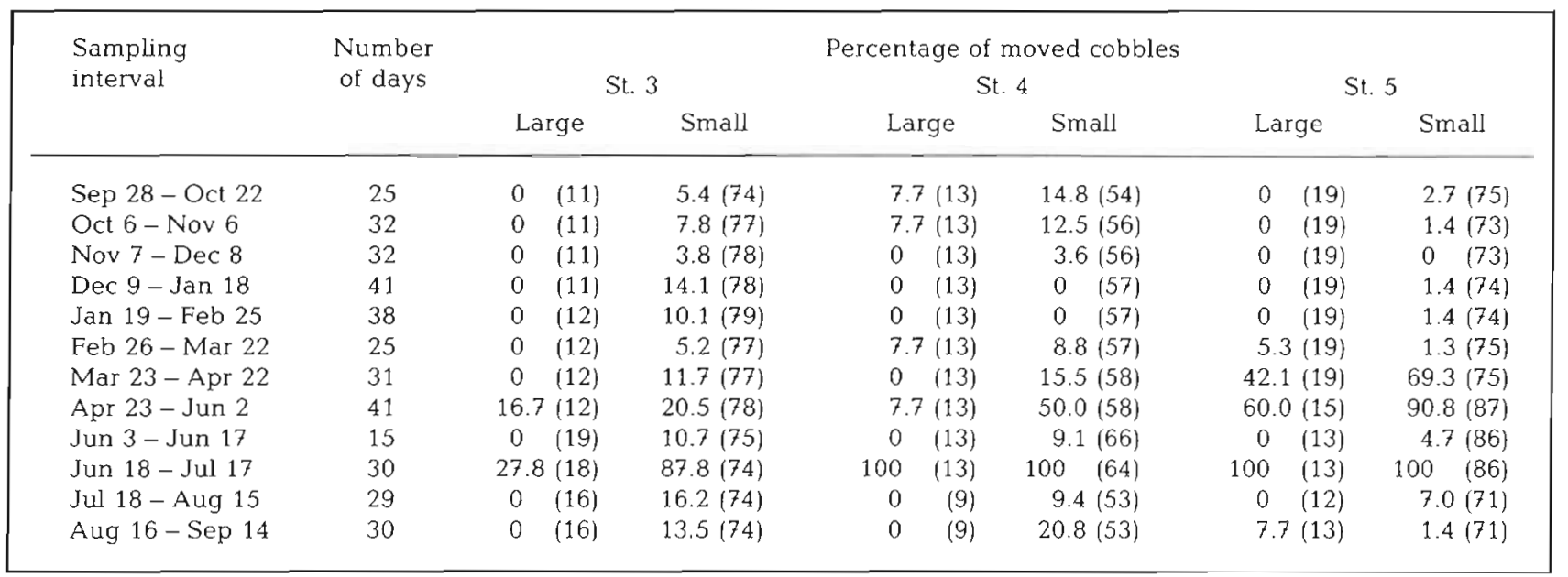

Table 3. Number of crabs of 4 common species collected by four 5 min searches from intertidal middle and lower levels of Sts 1 to 9. At Sts 7 to 9, where the intertidal zone was very narrow or did not exist. searches were carried out only in the lower level. M:

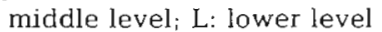

\begin{tabular}{|c|c|c|c|c|c|c|c|c|c|c|}
\hline Species & Level & St. 1 & St. 2 & St. 3 & St. 4 & St. 5 & St. 6 & St. 7 & St. 8 & St. 9 \\
\hline \multirow[t]{2}{*}{ Hemigrapsus penicillatus } & M & - & 40 & 48 & 72 & 77 & 15 & & & \\
\hline & $\mathrm{L}$ & 15 & 73 & 45 & 22 & 47 & 48 & - & - & - \\
\hline \multirow[t]{2}{*}{ Ptychognathus capillidigitatus } & M & - & - & 4 & - & - & - & & & \\
\hline & $\mathrm{L}$ & - & 40 & 32 & 13 & 3 & - & - & - & - \\
\hline \multirow[t]{2}{*}{ Ptychognathus ishii } & M & - & 204 & 5 & 3 & 9 & - & & & \\
\hline & $\mathrm{L}$ & - & 3 & 10 & 3 & 13 & 23 & - & - & - \\
\hline \multirow[t]{2}{*}{ Deiratonotus tondensis } & M & - & - & 1 & - & 4 & - & & & \\
\hline & $\mathrm{L}$ & - & - & 1 & 3 & 27 & 27 & 12 & - & - \\
\hline
\end{tabular}




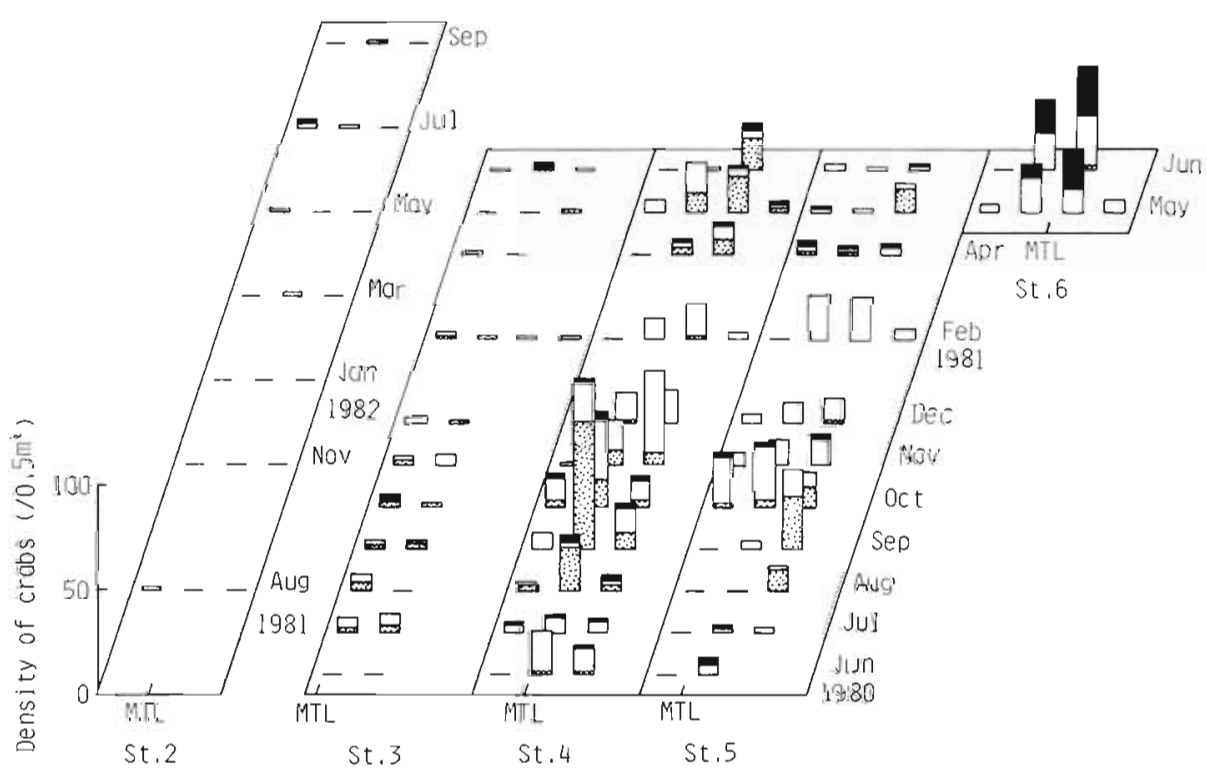

Fig. 3. Deiratonotus tondensis. Density $\left(0.5 \mathrm{~m}^{-2}\right)$ at each sampling point of St. 2 from Aug 1981 to Sep 1982, of Sts 3 to 5 from Jun 1980 to Jun 1981, and of St. 6 in May and Jun 1981. Tidal levels of sampling points decline from left to right at each station. Open histograms represent males and nonovigerous females combined, solid histograms ovigerous females, and dotted histograms unsexable juveniles. MTL: mean tide level tively. At St. 3, juvenile density was very low (4 crabs $0.5 \mathrm{~m}^{-2}$ max.) and at St. 2 only 2 juveniles were collected.

Sexable crabs ( $>4 \mathrm{~mm}$ in $\mathrm{CW}$ ) occurred commonly at the up-river stations, as did juveniles. At Sts 2 and 3 densities were consistently low, whereas at Sts 4 and 5 they were relatively high and varied monthly. Highest densities occurred in October and November, and lowest in August. Ovigerous females were collected from all stations, and a maximum density was recorded at St. 6 in May and June 1981. This species was common in the mid-and low-tide levels.

\section{Hemigrapsus penicillatus (Fig. 4)}

Juveniles were collected more abundantly at the down-river stations than at the up-river stations. At St. 2, juvenile numbers were relatively stable throughout the year, with a maximum density in November. At Sts 3 and 4, juveniles were collected mostly in the period from autumn to winter, and the highest abundance was found in December. At St. 5, few juveniles were collected. Juvenile crabs occurred generally in similar densities among the sampling points of the same station.

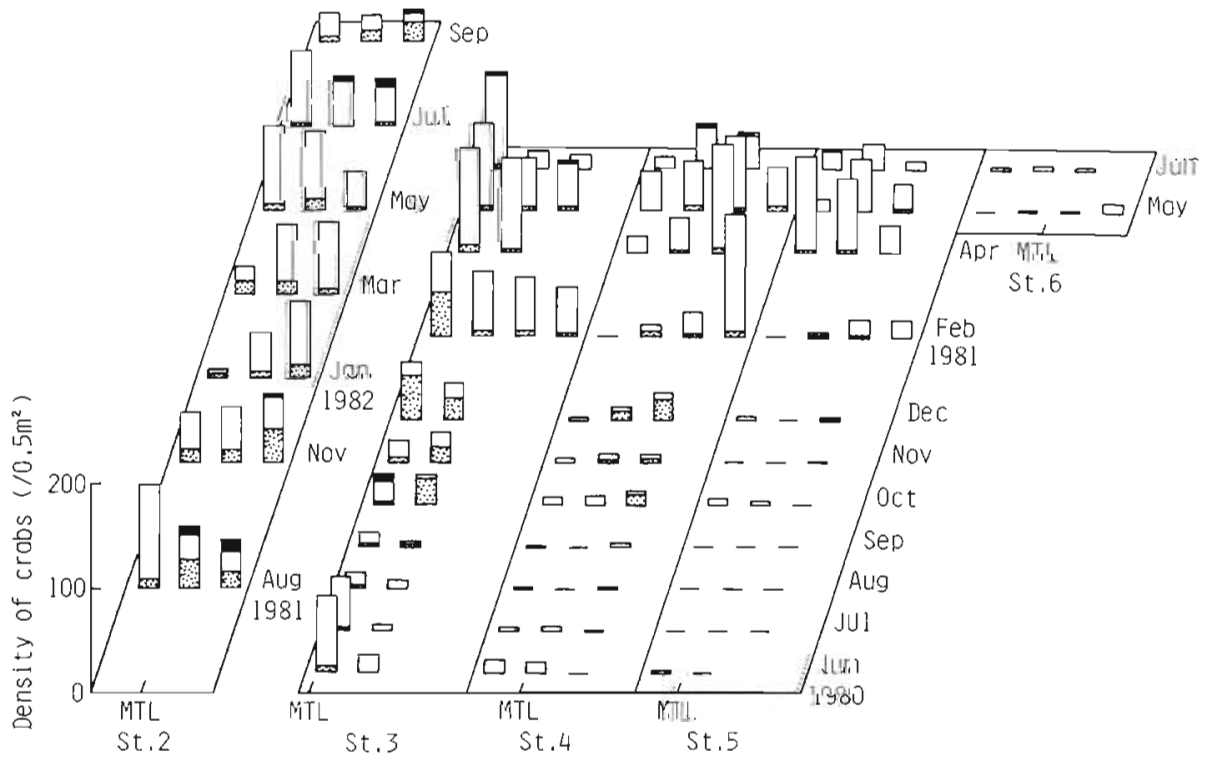

Fig. 4. Hemigrapsus penicillatus. Density $\left(0.5 \mathrm{~m}^{-2}\right)$ at each sampling point of Sts 2 to 6 . Legend as in Fig. 3 
The maximum densities of sexable crabs were recorded in April or May at all stations. At St. 2, densities decreased from autumn through to winter, but recovered to the previous high level in spring. At Sts 3 to 5, after declining to nearly zero in autumn, densities increased until spring. Thus, this species was distributed widely along the river length in spring, but was restricted to the down-river part from summer to winter. Ovigerous females were collected at Sts 2 to 4 , and were most abundant at St. 2 in August 1981. Sexable crabs occurred throughout the intertidal area, although their vertical distribution pattern varied with season and station. Ovigerous females were collected around the mid-and low-tide levels.

\section{Ptychognathus ishii (Fig. 5)}

Juvenile crabs occurred at Sts 2 to 5 , with densities being higher at St. 2 than at the other stations.

Sexable crabs were abundant at St. 2 throughout the year, although densities decreased from autumn to winter and increased from spring to summer. At Sts 3 and 4, densities were fairly constant, and at St. 5 number of crabs decreased gradually from the beginning of the survey. Ovigerous females were recorded from Sts 2 to 5 , and were most abundant at St. 2 in August 1981. The density of this species at St. 2 was 2 to 6 times higher at the middle sampling point than at the upper and lower points, but such a tendency was indistinct at the other stations. Ovigerous females were collected mainly around the mid-and low-tide levels.

\section{Ptychognathus capillidigitatus (Fig. 6)}

Juvenile crabs were collected at Sts 2 to 4 from October to July with no clear peak in abundance. At St. 5, they occurred only in June 1980.

Sexable crabs were common at Sts 2 to 4 , and were most abundant at St. 3. Few crabs were collected at Sts 5 and 6 . At St. 3, densities were high in June and July 1980 and, after a sharp decline in August, they were maintained at a similar level. Ovigerous females occurred at Sts 2 to 4 , and densities were similar between stations. This species showed a tendency to be restricted to near the low-tide level, typically exemplified at Sts 2 and 4. At Sts 3 and 4, the crabs collected from the additional lower sampling points exceeded those collected from regular sampling points in their densities.

\section{Seasonal population change}

Growth after settlement was estimated from the results of size-frequency distributions obtained from sampling stations for successive months (Fig. 7 to 10).

\section{Deiratonotus tondensis (Fig. 7)}

Early juveniles $(<3.0 \mathrm{~mm}$ in $\mathrm{CW})$ occurred from August to June, with the highest peak in September and another smaller peak in May. Most of the young males recorded in September were regarded as new recruits. These crabs continued to grow from autumn to

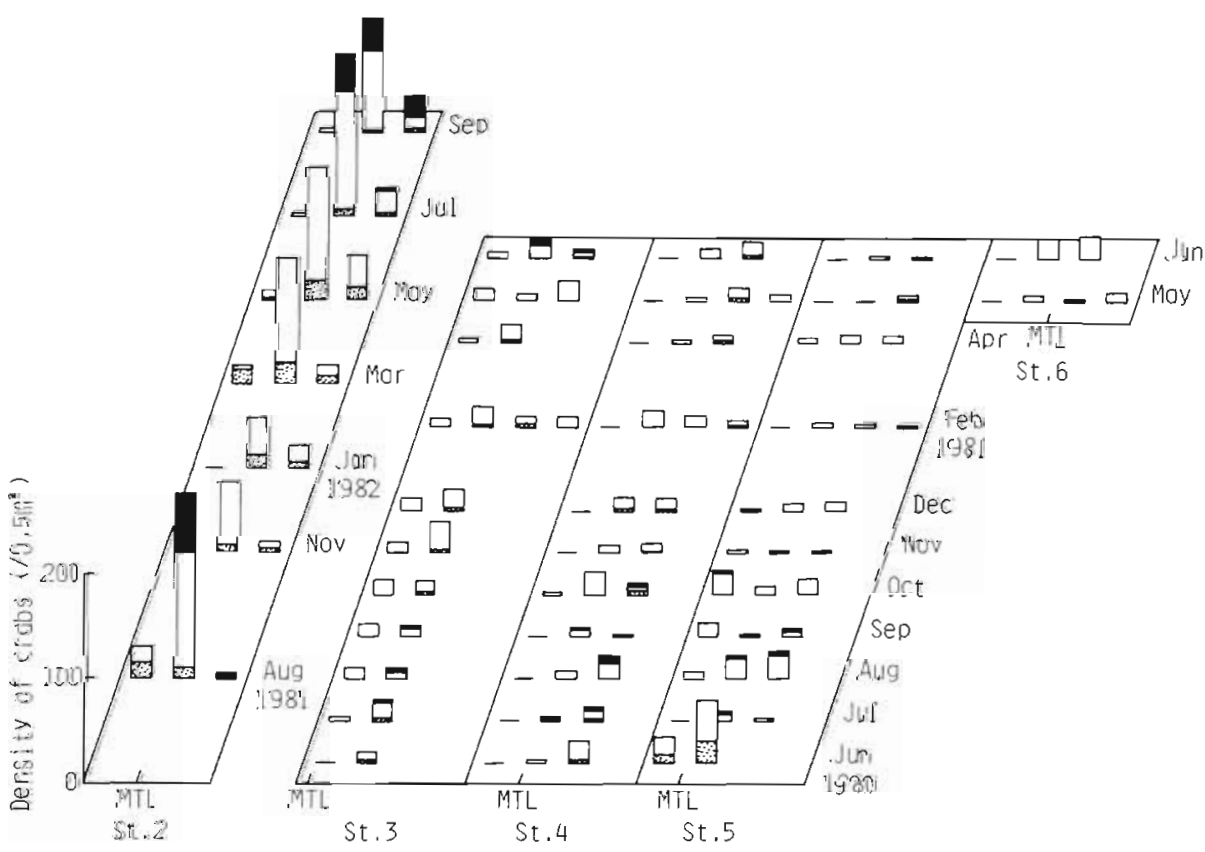

Fig. 5. Ptychognathus ishui. Density $\left(0.5 \mathrm{~m}^{-2}\right)$ at each sampling point of Sts 2 to 6 . Legend as in Fig. 3 
Fig. 6. Ptychognathus capilLidigitatus. Density $\left(0.5 \mathrm{~m}^{-2}\right)$ at each sampling point of Sts 2 to 6 . Legend as in Fig. 3

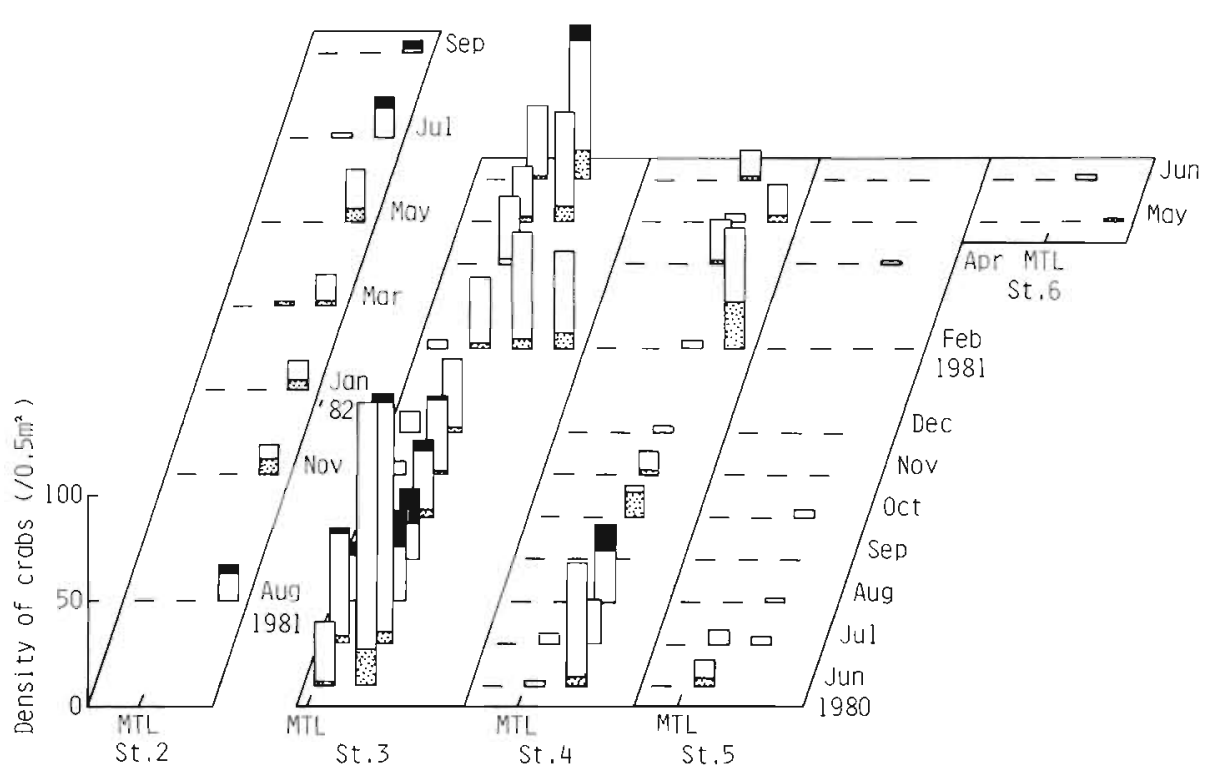

winter, with their size reaching 5.0 to $9.0 \mathrm{~mm}$ in February; their growth was difficult to follow afterwards. A similar temporal change of size-frequency distributions was found for females, from which females were suggested to bear eggs in their first spring and/or the following seasons (summer to autumn). It was also probable that some females began to breed in the autumn preceding their first winter.

\section{Hemigrapsus penicillatus (Fig. 8)}

At Sts 3 to 6 , the early juveniles $(<3.0 \mathrm{~mm}$ ) occurred from August through April with a peak in December. Young males $(<7.5 \mathrm{~mm}$ ) collected in February were regarded as new recruits. The population peak of this group could be traced until May. Although the size mode became obscure after May, most of the males in the period from June to August were considered to be the group which had recruited in the preceding autumn or winter. A similar temporal change of sizefrequency distributions was found for females, from which females were suggested to mature and bear eggs from summer to autumn following their first winter.

\section{Ptychognathus ishii (Fig. 9)}

Juvenile crabs occurred throughout the year at St. 2; their size mode was 1.0 to $2.0 \mathrm{~mm}$ in August and 2.0 to $4.0 \mathrm{~mm}$ from November through May. Young males $(<5.0 \mathrm{~mm})$ found in November to May were regarded
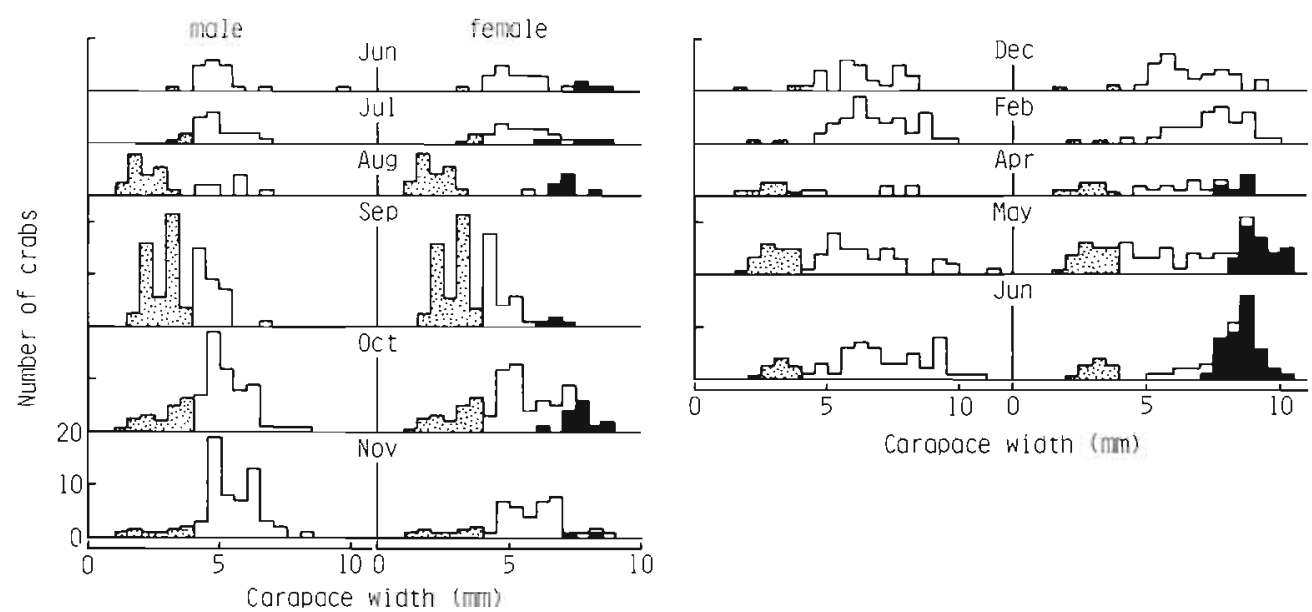

Fig. 7. Deiratonotus tondensis. Size-frequency distributions from Sts 3 to 6 combined from Jun 1980 to Jun 1981. Open histograms represent males or non-ovigerous females, solid histograms ovigerous females, and dotted histograms unsexable juveniles. Juveniles were divided equally into males and females on the assumption that the sex ratio is $1: 1$. (The sex ratio of sexable crabs was close to $1: 1$ ) 


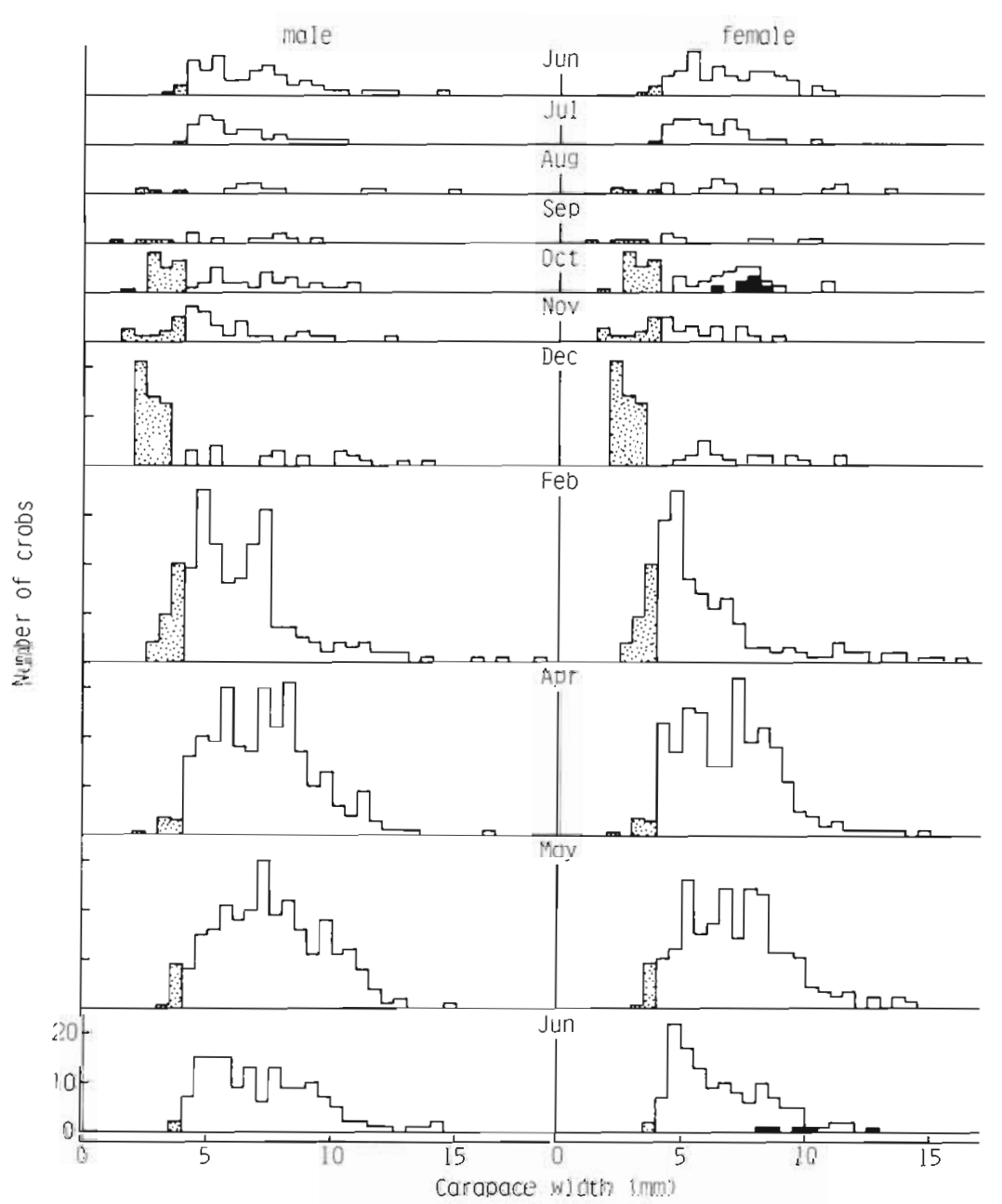

Fig. 8. Hemigrapsus penicillatus. Sizefrequency distributions from Sts 3 to 6 combined from Jun 1980 to Jun 1981 Legend as in Fig. 7 as new recruits. These crabs continued to grow and their size mode reached 5.0 to $7.0 \mathrm{~mm}$ in September. They merged with the larger groups and the size mode became obscure afterwards. Males larger than $5.0 \mathrm{~mm}$ in August were regarded as having overwintered at least once. Since these 'older' groups were recognizable through autumn and winter until May, some males overwintered possibly at least twice after settlement. Females followed a similar temporal change of size-frequency distributions to males. The size of
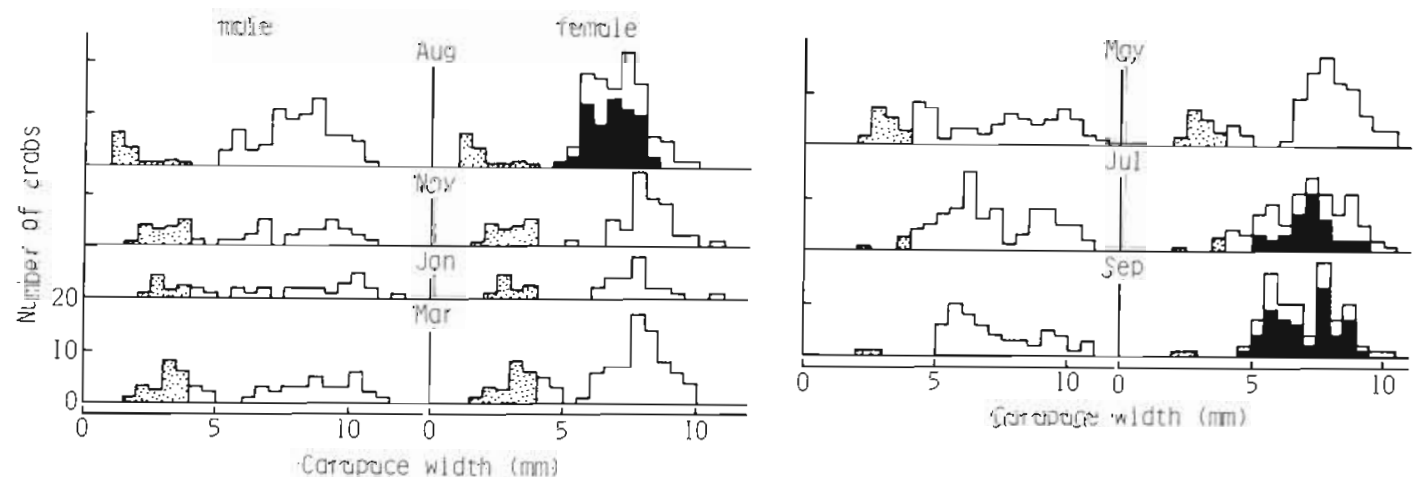

Fig. 9. Ptychognathus ishï. Size-frequency distributions from St. 2 from Aug 1981 to Sep 1982. Legend as in Fig. 7 
Fig. 10. Ptychognathus capillidigitatus. Size-frequency distributions from Sts 3 to $6 \mathrm{com}$ bined from Jun 1980 to Jun 1981. Legend as in Fig. 7
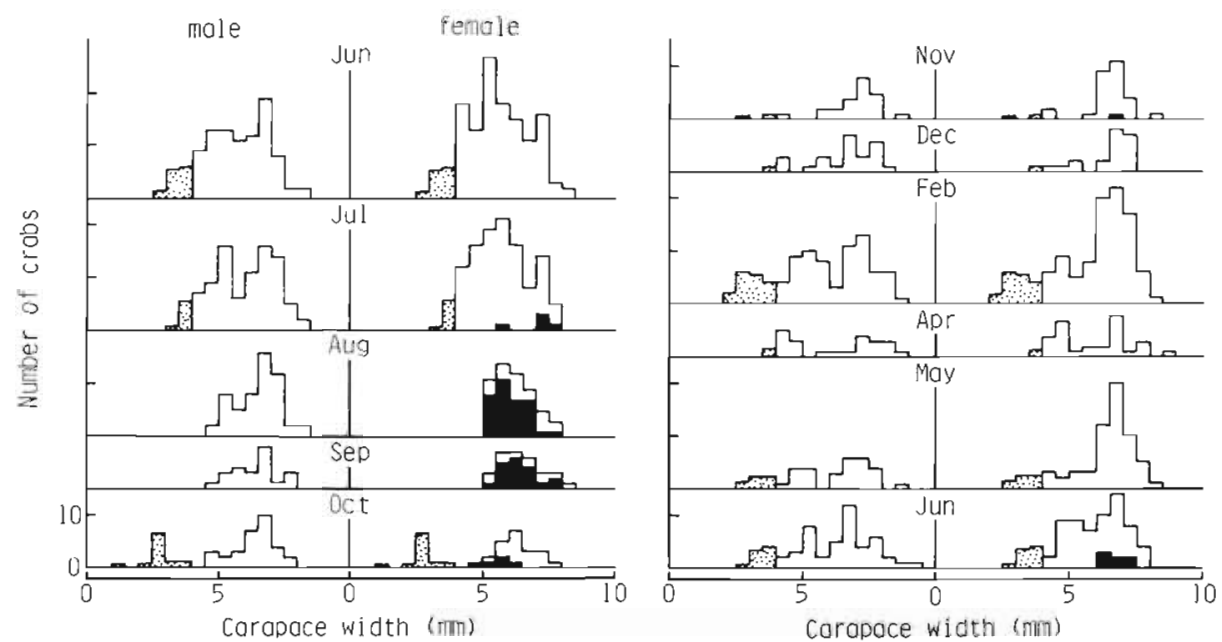

ovigerous females suggested that they began to breed in summer to autumn following their first winter at the earliest.

\section{Ptychognathus capillidigitatus (Fig. 10)}

Juvenile crabs occurred from October through July, In February, size modes of 2.5 to $3.5 \mathrm{~mm}, 4.5$ to $6.0 \mathrm{~mm}$ and 6.5 to $8.5 \mathrm{~mm}$ were discernible. The smaller two were regarded as young crabs which had settled in the preceding autumn to winter. They merged with the larger group by June and their size modes became obscure afterwards. The males in summer were, thus, composed of groups which had overwintered at least once. Since their size mode was recognizable until February, some males were presumed to have overwintered at least twice after settlement. Females followed a similar temporal change of size-frequency distributions to males. The size of the ovigerous females suggested that they began to breed in summer to autumn following their first winter. It was also probable that ovigerous females included the group which had overwintered twice.

\section{Survival rate}

Within species, estimated survival rates tended to decrease up-river except for Deiratonotus tondensis (Fig. 11); the natural logarithm of daily survival rate was significantly higher at St. 2 than at Sts 3 and 4 for Hemigrapsus penicillatus, at St. 3 than at St. 5 for Ptychognathus ishii, and at St. 2 than at St. 3 and at St. 3 than at St. 4 for Ptychognathus capillidigitatus (covariance analysis, $\mathrm{p}<0.05$ ). Comparing maximum survival rates between species, it was smallest in $D$.

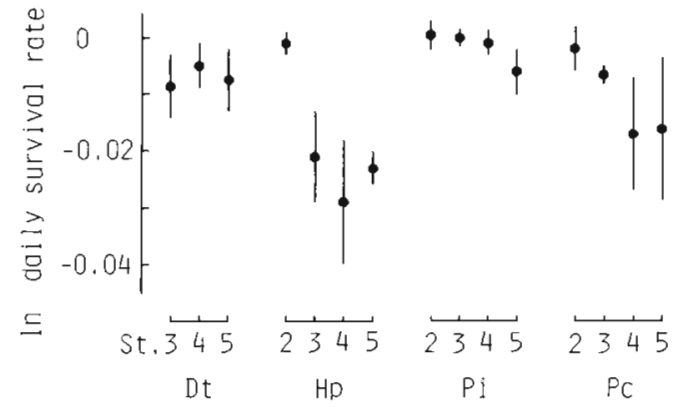

Fig. 11. Estimated survival rate of the 4 species at Sts 2 to 5. Mean values and $95 \%$ confidence intervals are shown. Dt: Deiratonotus tondensis; Hp: Hemigrapsus penicillatus; $\mathrm{Pi}$ Ptychognathus ishui; Pc: Ptychognathus capillidigitatus

tondensis, followed in order by $P$. capillidigitatus, $H$. penicillatus, and $P$. ishii, though none of these differences were significant.

\section{Reproduction}

Breeding season

Ovigerous females of Deiratonotus tondensis appeared from April through to November, which was the longest reproductive period of the 4 species (Fig. 12). Ovigerous females of Hemigrapsus penicillatus were included in all samples collected between July and November at St. 2, whereas they were collected only in October, May and June at Sts 3 to 5. Ptychognathus capillidigitatus and Ptychognathus ishii had similar annual breeding cycles, with ovigerous females present from June or July through to October or November; highest abundances were recorded in August to September. 


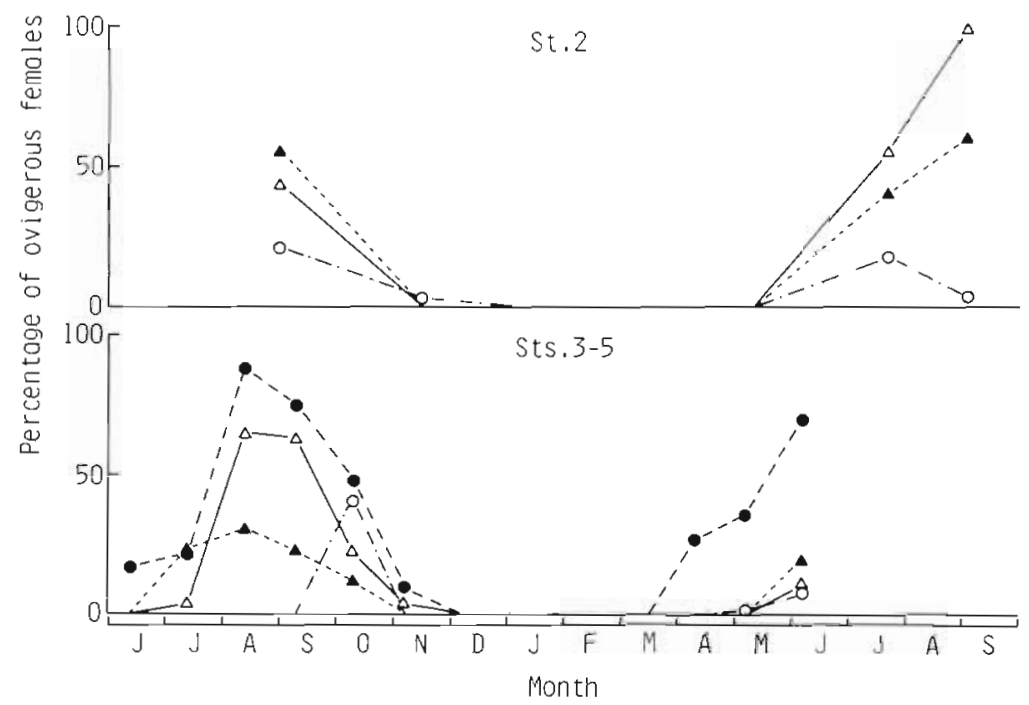

Fig. 12. Seasonal variation in percent ovigerous females at St. 2 (Aug 1981 to Sep 1982) and Sts 3 to 5 (Jun 1980 to Jun 1981). (@) Deiratonotus tondensis; (O) Hemigrapsus penicillatus; (4)

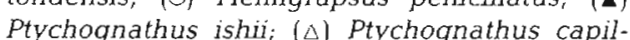
bidigitatus
Egg size

Mean egg volume was calculated from the length and width on the assumption that an egg is a spheroid (Table 4). Egg volume was larger for Stage III than Stage I within each species, though at a given stage it showed little variation among individuals. At both stages, the volume was largest in Deiratonotus tondensis, followed in order by Ptychognathus ishii, Hemigrapsus penicillatus, and Ptychognathus capillidigitatus.

\section{Egg number}

Log number of eggs per brood was linearly related $(p<0.01)$ to $\log$ female carapace width for all 4 species
(Fig. 13). Covariance analysis showed that the slopes of the regression lines were not significantly different except between Hemigrapsus penicillatus and Ptychognathus ishii $(\mathrm{p}<0.01)$ and between Deiratonotus tondensis and $P$. ishii $(p<0.05)$. Elevations were significantly different $(p<0.01)$ between all other pairs of species. The egg number per brood was smallest in D. tondensis, and largest in Ptychognathus capillidigitatus among similar-sized females of the 4 species.

\section{Brood weight per body weight}

The ratio of brood weight to body weight showed little variation within species, and was not correlated with body size $(p>0.1)$. As shown in Table 4 , the mean

Table 4. Egg volume $\left(\mathrm{mm}^{3}\right)$, brood weight per body weight, incubation period (d) and brood number per year of 4 estuarine crabs Numbers in parentheses indicate sample size (number of individuals)

\begin{tabular}{|c|c|c|c|c|c|c|c|c|}
\hline & \multicolumn{2}{|c|}{$\begin{array}{c}\text { Deiratonotus } \\
\text { tondensis }\end{array}$} & \multicolumn{2}{|c|}{$\begin{array}{l}\text { Hemigrapsus } \\
\text { penicillatus }\end{array}$} & \multicolumn{2}{|c|}{$\begin{array}{c}\text { Ptychognathus } \\
\text { ishii }\end{array}$} & \multicolumn{2}{|c|}{$\begin{array}{l}\text { Ptychognathus } \\
\text { capillidigitatus }\end{array}$} \\
\hline \multicolumn{9}{|l|}{ Egg volume $\mathrm{mm}^{3}$ (mean $\left.\pm \mathrm{SD}\right)$} \\
\hline Stage I & $\begin{array}{r}0.0215 \\
\pm 0.0026\end{array}$ & (18) & $\begin{array}{r}0.0126 \\
\pm 0.0009\end{array}$ & (7) & $\begin{array}{r}0.0159 \\
\pm 0.0037\end{array}$ & (13) & $\begin{array}{r}0.0116 \\
\pm 0.0019\end{array}$ & $\{10\}$ \\
\hline Stage III & $\begin{array}{r}0.0294 \\
\pm 0.0025\end{array}$ & (17) & $\begin{array}{r}0.0197 \\
\pm 0.0048\end{array}$ & $(7)$ & $\begin{array}{r}0.0233 \\
+0.0024\end{array}$ & $(16)$ & $\begin{array}{r}0.0180 \\
\pm 0.0012\end{array}$ & $(12)$ \\
\hline Brood wt per body wt (mean $\pm S D$ ) & $\begin{array}{r}0.167 \\
\pm 0.027\end{array}$ & $(47)$ & $\begin{array}{r}0.118 \\
\pm 0.026\end{array}$ & (31) & $\begin{array}{r}0.207 \\
\pm 0.034\end{array}$ & $(22)$ & $\begin{array}{r}0.201 \\
\pm 0.023\end{array}$ & (18) \\
\hline Incubation period, $d$ (mean $\pm S D$ ) & $\begin{array}{r}17.7 \\
+1.19\end{array}$ & $(11)$ & $\begin{array}{c}12.4 \\
\pm 1.57\end{array}$ & (11) & $\begin{array}{l}15.0 \\
\pm 0.58\end{array}$ & (7) & $\begin{array}{c}15.0 \\
\pm 1.41\end{array}$ & (2) \\
\hline Water temperature ${ }^{\circ} \mathrm{C}$ & \multicolumn{2}{|c|}{$22.9-28.2$} & \multicolumn{2}{|c|}{$22.6-28.1$} & \multicolumn{2}{|c|}{$24.6-27.9$} & \multicolumn{2}{|c|}{$23.2-27.9$} \\
\hline Brood number per year & \multicolumn{2}{|l|}{$5-6$} & \multicolumn{2}{|l|}{$2-3$} & \multicolumn{2}{|l|}{$2-4$} & \multicolumn{2}{|l|}{$3-4$} \\
\hline
\end{tabular}




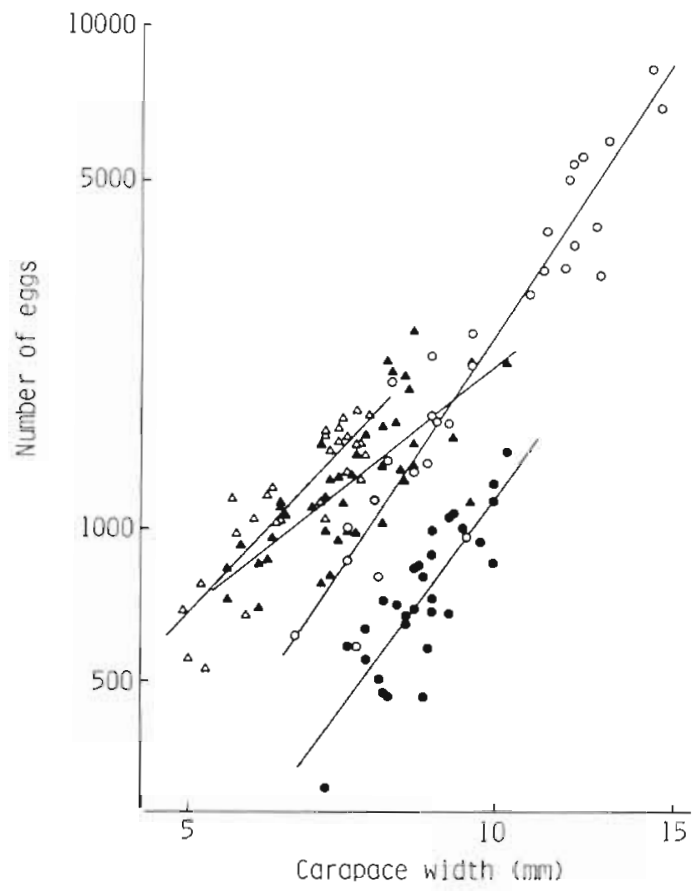

Fig. 13. Log number of eggs per brood versus log carapace width. (-) Deiratonotus tondensis, $\log \mathrm{Y}=2.760 \log \mathrm{X}+$ $0.297, \mathrm{r}=0.826 ;(0)$ Hemigrapsus penicillatus, $\log \mathrm{Y}=3.040$ $\log \mathrm{X}+0.335, I=0.941_{i}$ ( $\left.\mathbf{1}\right)$ Ptychognathus ishii, $\log \mathrm{Y}=$ $1.611 \log X+1.707, r=0.752 ;(\Delta)$ Ptychognathus capillidigitatus, $\log Y=2.164 \log X+1.317, r=0.886$

value decreased in the order Ptychognathus ishii, Ptychognathus capillidigitatus, Deiratonotus tondensis, Hemigrapsus penicillatus.

\section{Brood number estimated from incubation period}

The number of broods from June to October was estimated using the mean incubation period obtained (Table 4), since water temperatures in the rearing tank corresponded to those in the field in the same period. Thus, Deiratonotus tondensis was estimated to produce 4 to 5 broods, Hemigrapsus penicillatus 2 to 3 broods, Ptychognathus ishii 2 to 4 broods, and Ptychognathus capillidigitatus 3 to 4 broods. These values may nearly equal brood numbers per year for $H$. penicillatus, $P$. ishii and $P$. capillidigitatus, as this period is almost the same as their breeding seasons. $D$. tondensis, however, was also ovigerous from April to May, so it may produce 5 to 6 broods per year.

\section{DISCUSSION}

Besides the present 4 species of crabs, i.e. Deiratonotus tondensis, Hemigrapsus penicillatus, Ptychognathus ishii and Ptychognathus capillidigitatus, 2 further species, Eriocheir japonicus De
Haan and Sesarma (Holometopus) dehaani (H. Milne Edwards), were recorded from intertidal cobble shores of the Tonda River Estuary. In E. japonicus and $S$. dehaani, all individuals collected were classed as juveniles. Adult crabs of E. japonicus usually inhabit the fresh water area of the river, but migrate downriver close to the mouth during the breeding season, lay eggs and release larvae (Morita 1974). S. dehaani inhabits the reed marsh and bank near the estuary abundantly (Hashiguchi \& Miyake 1967), and in the breeding season the ovigerous females come out to the riverside to release their larvae (Saigusa 1978). Probably, these 2 species use intertidal cobble shores as their juvenile habitat, but emigrate to the adult habitat as they grow.

In contrast, in the 4 species of crabs currently studied, both juveniles and adults occurred in intertidal cobble shores. Juveniles, ovigerous females and other sexable crabs of Hemigrapsus penicillatus occurred abundantly in the down-river part throughout the year, though sexable crabs occurred also at the upriver stations from winter to spring. In the other 3 species, the distribution pattern remained unchanged seasonally, with Deiratonotus tondensis abundant in the up-river part, and Ptychognathus ishii and Ptychognathus capillidigitatus in the down-river part. Also, the vertical distribution pattern at each station showed little seasonal variation; $P$. capillidigitatus was abundant at low-tide level, while the others were common around the mid-and low-tide levels. Within each species, juveniles, ovigerous females and other sexable crabs had similar distribution patterns along the length of the estuary. Consequently, these 4 crab species, after settlement, scarcely change their habitats with either growth or season, in contrast to Eriocheir japonicus and Sesarma (Holometopus) dehaani.

The reproductive attributes of the present 4 species are summarized with their distributions and mortalities in Table 5. Egg size was largest in Deiratonotus tondensis, followed in order by Ptychognathus ishii, Hemigrapsus penicillatus, and Ptychognathus capil-

Table 5. Summary of distribution, mortality, and reproductive attributes of 4 estuarine crabs. Dt: Deiratonotus tondensis; $\mathrm{Hp}$ : Hemigrapsus penicillatus; Pi: Ptychognathus ishij; $\mathrm{PC}$ : Ptychognathus capillidigitatus

\begin{tabular}{|ll|}
\hline Distribution & Up-river: $\mathrm{Dt}$ \\
& Down-river: $\mathrm{Hp}, \mathrm{Pi}, \mathrm{PC}$ \\
Mortality & $\mathrm{Dt}>\mathrm{PC}>\mathrm{Hp}>\mathrm{Pi}$ \\
Egg size & $\mathrm{Dt}>\mathrm{Pi}>\mathrm{Hp}>\mathrm{Pc}$ \\
Egg number per brood & $\mathrm{Pc}>\mathrm{Hp}, \mathrm{Pi}>\mathrm{Dt}$ \\
Brood weight per body weight & $\mathrm{Pi}>\mathrm{PC}>\mathrm{Dt}>\mathrm{Hp}$ \\
Brood number per year & $\mathrm{Dt}>\mathrm{Pc}>\mathrm{Pi}>\mathrm{Hp}$ \\
Reproductive effort per year & $\mathrm{Dt}>\mathrm{Pi}, \mathrm{PC}>\mathrm{Hp}$
\end{tabular}


lidigitatus. Shokita (1979) showed that inland water macrurans inhabiting upper reaches have larger eggs, their larvae hatch in a more advanced stage, and their larval stage periods are shorter, compared with those in lower reaches. Various selective pressures for enlarging egg size have been pointed out: greater investment of nutrients into the egg stage under conditions hard for offspring to gain food (Ito 1978) and, in the case of inland shrimps, decreased molt frequency when minerals are lacking and shortened larval periods under unstable conditions (Shokita 1979). Thus, egg size is generally considered to depend on environmental conditions at the larval stage. In the 4 estuarine crabs currently studied, there was a tendency for up-river species to have larger eggs than those down-river, in common with inland macrurans. But, lacking information on their larval life, it is uncertain whether a similar analysis as for inland macrurans can be applied to these estuarine crabs.

Log egg number per brood was a linear function of log body size for each species, and comparison between species in similar-sized females showed that egg number decreased in the order Ptychognathus capillidigitatus, Ptychognathus ishii or Hemigrapsus penicillatus, Deiratonotus tondensis. Taking egg size difference among the 4 species into consideration, the tendency is recognized that a species whose egg size is larger has a smaller number of eggs per brood in similar-sized females. If the total amount of reproductive matter per brood is fixed, the number of eggs is determined by how much matter is provided for each egg (Hines 1982). In the present crabs, egg size varied considerably, while the ratios of brood weight to body size were somewhat similar, resulting in the observed trade-off between egg size and number of eggs per brood.

Monthly size-frequency distributions suggest that the 4 crab species matured after their first overwintering and that all of them had annual breeding cycles. The ratio of brood weight per body weight has often been used as an index of current reproductive effort (Tinkle 1969, Pianka \& Parker 1975). Since the present crabs have annual breeding cycles, reproductive effort per year can be compared among them using the ratio of brood weight to body weight multiplied by the number of broods per year. Hemigrapsus penicillatus had the smallest value in both the ratio of brood weight to body weight and the number of broods per year of the 4 species. Deiratonotus tondensis showed about $20 \%$ lower rate of brood weight per body weight than Ptychognathus ishii and Ptychognathus capillidigitatus, but had more than 1.5 times as many broods per year than the other species. On this evidence, $D$. tondensis has a higher reproductive effort per year than the others.
The bet-hedging theory (Murphy 1968, Schaffer 1974, Stearns 1976) predicts that fluctuating environments which cause high adult mortality favor early maturity, increased immediate reproductive effort and shorter lifespans. Estuarine environments fluctuate under not only the periodical cycle of tides but also the unpredictable change of river flow. Especially in the upper reaches of this estuary, swift currents, caused by heavy rainfall, occur. These move surface cobbles considerably, as shown in our results for cobble movement. We have no evidence that cobble movements in the upper reaches heighten adult crab mortality. However, the following facts may indicate that Deiratonotus tondensis living in such an environment of the upper reaches has higher mortality than the other down-river species. First, monthly size-frequency distributions suggested that some individuals of the down-river species Ptychognathus ishii and Ptychognathus capillidigitatus may survive until the second breeding season, whereas in the up-river species $D$. tondensis breeding after the second overwintering was doubtful. Secondly, although estimated survival rate of each species varied considerably among stations, the maximum value was lower in $D$. tondensis than in the others, though the differences were not significant. If it is true that $D$. tondensis has higher mortality than the other species, higher reproductive effort of this species can be explained on the bet-hedging theory.

It is possible that the variation in reproductive effort could also be related to other factors. The breeding period of subtropical or tropical species of marine invertebrates generally tends to be shortened in the colder part of its geographical range (Giese \& Pearse 1974). Deiratonotus tondensis and Hemigrapsus penicillatus are species distributed mainly in the temperate zone, while Ptychognathus ishii and Ptychognathus capillidigitatus are subtropical species (Sakai 1976, pers. obs.). Since the Tonda River Estuary is located near the northern limit of the geographical distribution range of the latter 2 species, their breeding period may be shortened here, which may have caused lower reproductive effort per year. Furthermore, Hirshfield \& Tinkle (1975) predicted that reproductive effort should vary inversely with the variance in mortality of the immature period. There is, however, little information on the mortality of larval stages for the present 4 species. Studies on the annual change in the densities of both newly settled juveniles and adults and on the migration of their planktonic larvae into and out of the estuary are necessary to estimate larval mortality.

Acknowledgements. We thank Prof. E. Harada, Dr. M. B. Jones and 3 anonymous reviewers for critically reading our 
manuscript. We thank also Dr. S. Nakamura for estimating the river flow, Messrs. S. Ohgaki, T. Higashimine and K. Okita for assistance in the field, and $\mathrm{Mr} \mathrm{N}$. Abe for statistical advice. This work was supported in part by a Grant-in-Aid for Special Project Research on Biological Aspects of Optimal Strategy and Social Structure from the Japan Ministry of Education, Science and Culture.

\section{LITERATURE CITED}

Cassie, R. M. (1954). Some uses of probability paper in the analysis of size frequency distributions. Aust. J. mar. Freshwat. Res. 5: 513-522

Day, J. H. (1981). Estuarine ecology. A. A. Balkema, Rotterdam

Giese, A. C., Pearse, J. S. (1974). Reproduction of marine invertebrates. Vol. I. Academic Press, New York

Griffin, D. J. G. (1971). The ecological distribution of grapsid and ocypodid shore crabs in Tasmania. J. Anim. Ecol. 40: $597-621$

Hashiguchi, Y., Miyake, S. (1967). Ecological studies of marsh crabs, Sesarma spp. II. Habitats, copulation and egg-bearing season. Sci. Bull. Fac. Agric. Kyusyu Univ. 23: 81-89 (In Japanese)

Hines, A. H. (1982). Allometric constraints and variables of reproductive effort in brachyuran crabs. Mar. Biol. 69: 309-320

Hirshfield, M. F., Tinkle, D. W. (1975). Natural selection and the evolution of reproductive effort. Proc. natn. Acad. Sci. U.S.A. 72: $2227-2231$

Ito, Y. (1978). Comparative ecology. Iwanami, Tokyo. (In Japanese)

Japan Meteorological Agency (1983). Tide tables for the year 1984. Japan Meteorological Agency, Tokyo

Jones, M. B. (1977). Limiting factors in the distribution of intertidal crabs (Crustacea: Decapoda) in the AvonHeathcote Estuary, Christchurch. N. Z. Jl mar. Freshwat. Res. 10: 577-587

Jones, M. B. (1980). Reproductive ecology of the estuarine burrowing mud crab Helice crassa (Grapsidae). Estuar. coast. mar. Sci. 11: 433-443

Jones, M. B., Simons, M. J. (1983). Latitudinal variation in reproductive characteristics of a mud crab, Helice crassa (Grapsidae). Bull. mar. Sci. 33: 656-670

Lauff, G. H. (1967). Estuaries. American Association for the Advancement of Science, Washington, D.C.

Little, C., Smith, L. P. (1980). Vertical zonation on rocky shores in the Severn estuary. Estuar. coast. mar. Sci. 11: $651-669$

Morita, T (1974). On mating behavior of Eriocheir japonicus De Haan. Res. Crustacea 6: 31-47. (In Japanese with English summary)

Murphy, G. I. (1968). Pattern in life history and the environment. Am. Nat. 102: 391-403

Ono, Y. (1962). On the habitat preference of ocypoid crabs. I. Mem. Fac. Sci., Kyusyu Univ, Ser. E 3: 143-163

Ono, Y. (1965). On the ecological distribution of ocypoid crabs in the estuary. Mem. Fac. Sci., Kyusyu Univ., Ser. E 4: $1-60$

Pianka, E. R., Parker, W. S. (1975). Age-specific reproductive tactics. Am. Nat. 109: 453-464

Pillay, K. K., Ono, Y. (1978). The breeding cycles of two species of grapsid crabs (Crustacea, Decapoda) from the North Coast of Kyusyu, Japan. Mar. Biol. 45: 237-248

Saigusa, M. (1978). Ecological distribution of three species of the genus Sesarma in winter season. Zool. Mag., Tokyo 87: $142-150$

Sakai, T. (1976). Crabs of Japan and the adjacent seas. Kodansha, Tokyo

Sakai, T. (1983). Description of new genera and species of Japanese crabs, together with systematically and biogeographically interesting species. (I). Res. Crustacea 12: $1-44$

Schaffer, W. M. (1974). Optimal reproductive effort in fluctuating environments. Am. Nat. 108: 783-790

Seiple, W. (1979). Distribution, habitat preference and breeding periods in the crustaceans Sesarma cinereum and $S$. reticulatum (Brachyura: Decapoda: Grapsidae). Mar. Biol. 52: $77-86$

Shokita, S. (1979). The distribution and speciation of the inland water shrimps and prawns from the Ryukyu Islānds. II. Bull. Coll. Sci., Univ. Ryukyus 28: 193-278. (In Japanese)

Simons, M. J., Jones, M. B. (1981). Population and reproductive biology of the mud crab, Macrophthalmus hirtipes (Jacquinot, 1853) (Ocypodidae), from marine and estuarine habitats. J. nat. Hist. 15: 981-994

Snelling, B. (1959). The distribution of intertidal crabs in the Brisbane River. Aust. J. mar. Freshwat. Res. 10:67-83

Stearns, S. C. (1976). Life-history tactics: a review of the ideas. Q. Rev. Biol. 51: 3-47

Takeda, M. (1984). A new crab of the family Grapsidae from Japan. Bull. natn. Sci. Mus., Tokyo, Ser. A 10: 117-120

Tinkle, D. W. (1969). The concept of reproductive effort and its relation to the evolution of life histories of lizards. Am Nat. 103: 501-516 